УДК 343.9

\title{
Э.P. Гафурова
}

\section{К ВОПРОСУ О КРИМИНАЛИЗАЦИИ ПРЕСТУПНЫХ ДЕЯНИЙ, СВЯЗАННЫХ С РАСПРОСТРАНЕНИЕМ КОРОНАВИРУСНОЙ ИНФЕКЦИИ}

В статье рассмотрены вопросы совершенствования российского уголовного законодательства об ужесточении ответственности в условиях коронавирусной инфекции. Автором был проведен анализ эффективности мер ужесточения уголовной ответственности за нарушение карантинных мероприятий в целях противодействия распространению коронавирусной инфекции в зарубежных странах и представлены предложения по совершенствованию российского уголовного законодательства, с учетом данных проведенного среди граждан Российской Федерации социологического исследования. В целях изучения норм уголовного законодательства, введенных в действие Федеральным законом № 100-Ф3 от 01.04.2020 г., об ответственности за распространение заведомо ложной информации об обстоятельствах, представляющих угрозу жизни и безопасности граждан, приведены примеры судебной практики. На основе опыта зарубежных стран отмечается перспективное ужесточение юридической ответственности в условиях распространения коронавирусной инфекции в России.

Ключевые слова: юридическая ответственность, уголовная ответственность, ужесточение ответственности, криминализация, коронавирусная инфекция, пандемия, ограничения, недостоверная информация.

DOI: $10.35634 / 2412-9593-2021-31-2-243-250$

В связи со сложившейся ситуацией, связанной с пандемией коронавируса (SARS-CoV-2), который вызывает опасное инфекционное заболевание COVID-19, возникшей в конце декабря 2019 г. в одной из провинций Китая, рядом государств были приняты меры по предупреждению распространения коронавирусной инфекции.

Всемирная организация здравоохранения 30 января 2020 г. объявила пандемию коронавируса COVID-19, которая оказала разрушительное воздействие на экономическую сферу как всего мира, так и отдельных государств, а также на нормальную жизнедеятельность граждан. Несмотря на мировую опасность коронавируса и сложность борьбы с ним - это явление контролируемое и управляемое в том случае, если обеспечивается неукоснительное соблюдение всех необходимых мер безопасности. Единственным и эффективным способом противодействовать его стремительному распространению, по мнению большинства ученых [7. С. 58] и как свидетельствует опыт отдельных государств, является обеспечение условий соблюдения ограничений или карантина.

Коронавирусы представляют собой семейство вирусов, включающее на май 2020 г. 43 вида РНК-содержащих вирусов, объединённых в два подсемейства, которые поражают млекопитающих (включая человека), птиц и земноводных [8]. Механизмы передачи коронавирусной инфекции (SARS-CoV-2) различны: воздушно-капельный, воздушно-пылевой, контактный. Поэтому государствами были приняты решения о введении различного рода ограничений, направленных на предупреждение распространения новой коронавирусной инфекции.

Следует отметить, что Постановлением Правительства Российской Федерации был введен п. 16 «коронавирусная инфекция» в Перечень заболеваний, представляющих опасность для окружающих [4].

На сегодняшний день Россия по числу зараженных вышла на 4-е место в мире (более 3,5 млн случаев заражения) [10]. Мы видим, что важность введения и соблюдения ограничительных мер в целях улучшения эпидемиологической обстановки и снижения уровня распространение COVID-19 очень высока.

Как и в ряде других стран, в РФ действуют административные меры, которые способствуют обеспечению предупреждения заболеваемости COVID-19 среди граждан, при их неукоснительном соблюдении [7. С. 57]. К числу таких ограничений в связи с коронавирусом (COVID-19) относят следующие: ограничение авиасообщений; обязательное соблюдение масочного режима; временное ограничение движения через пункты пропуска на государственной границе РФ, а также через сухопутный участок российско-белорусской границы; автомобильные, железнодорожные, пешеходные, речные и смешанные пункты пропуска; организация и проведение официальных физкультурных и спортивных мероприятий на территории РФ с измерением температуры участникам и персоналу, входящим на объект, с использованием бесконтактных термометров, а также иные меры. 
Большинством зарубежных стран в целях профилактики распространения пандемии коронавирусной инфекции также были введены ограничительные меры защиты: карантины, самоизоляции, ограничения перемещений, комендантский час, закрытие предприятий, перевод сотрудников на удаленный режим работы и др.

Можно сделать вывод о том, что значительная часть введенных мер во всех странах мира схожа, лишь некоторые из них отличаются наиболее усиленными методами защиты в силу повышенной опасности распространения коронавируса.

Наряду с введением в странах ограничительных мер было криминализировано и законодательство об ответственности за их несоблюдение и нарушения карантинного режима, которое существенно различается по степени и размеру наказания. Так, для обеспечения санитарно-эпидемиологической безопасности, защиты жизни и здоровья граждан были конкретизированы положения уголовного законодательства Китая, которые на сегодня содержат достаточно суровые санкции в части предупреждения распространения коронавирусной инфекции. К примеру, уголовное законодательство Китая позволяет привлечь к ответственности за сам факт несообщения о наличии симптомов заболевания в случае нахождения лица в общественном месте или за необращение в медицинскую организацию после посещения населенных пунктов, отличающихся высоким уровнем заболеваемости. А в случае несоблюдения карантинных предписаний наступает ответственность по ст. 115 Уголовного кодекса Китайской Народной Республики (далее - УК КНР), то есть за преступление, посягающее на общественную безопасность, опасным способом, наказывается «лишением свободы на срок свыше 10 лет, бессрочным лишением свободы или смертной казнью» [11].

Также ст. 141 и 142 УК КНР предусматривают ответственность за производство и реализацию поддельных либо некачественных лекарственных средств, в данной ситуации касающихся профилактики коронавирусной инфекции, повлекших вред здоровью человека или создающих угрозу его причинения. Размер наказания за такие противоправные действия варьируется: лишение свободы на срок от 3 до 10 лет, на срок свыше 10 лет, бессрочное лишение свободы или смертная казнь, а также одновременно или в качестве самостоятельного наказания - штраф в сумме от $50 \%$ до 2-кратного размера стоимости реализованной продукции или конфискация имущества [11].

На наш взгляд, уголовное законодательство Китая позволяет в современных условиях осуществлять предупреждение распространения короновирусной инфекции COVID-19 несмотря на отсутствие в законодательстве специальной нормы об этом, то есть содержание норм УК КНР предоставляет возможность правоприменителям привлекать к ответственности лиц, нарушающих карантинные меры или иным образом способствующих отклонению от соблюдения принятых государством ограничительных мер.

Считаем необходимым обратить внимание на ужесточение уголовной ответственности в таких странах, как Израиль и Аргентина, которые также содержат суровые меры ответственности против распространения COVID-19.

Основополагающим уголовным законом в Израиле является Закон об уголовном праве 1977 г., так как кодификационное законодательство отсутствует [12]. В связи с последними событиями пандемии в Израиле была ужесточена уголовная ответственность за нарушение режима карантина. К примеру, ст. 218 «Деяние, которое может распространить болезнь» Закона об уголовном праве 1977 г. содержит санкцию о тюремном заключении сроком на 3 года, если преступление совершено по халатности. В случае если лицо совершило такое деяние злонамеренно, то наказание следует в виде тюремного заключения сроком на 7 лет [12].

Далее, ст. 287 «Нарушение законного распоряжения» Закона об уголовном праве 1977 г., то есть нарушение распоряжения или указа, касающегося введенных ограничений, например, о самоизоляции в целях предотвращения распространения коронавирусной инфекции, наказывается тюремным заключением сроком на 4 года [12].

Таким образом, для привлечения к уголовной ответственности в Израиле необязательно нарушать карантин, преступлением является сам факт несоблюдения установленных правовыми актами ограничений.

Статьей 205 Уголовного кодекса Аргентины (далее - УК Аргентины) за нарушение санитарных мер по борьбе с эпидемиями, которые предписаны компетентным органом, предусмотрено лишение свободы на срок от 6 месяцев до 2 лет [13]. Для лиц, которые распространяют опасную для людей инфекционную болезнь намеренно, установлено наказание в виде тюремного заключения от 3 до 15 
лет (ст. 202 УК Аргентины) [13]. В случае если распространение вируса было совершено заболевшим лицом по неосторожности, то санкция ст. 203 УК Аргентины устанавливает штрафы в размере от 5 до 100 тыс. долларов [13].

В рамках анализа зарубежного законодательства нами был проведен социологический опрос среди граждан, проживающих на территории Российской Федерации, на тему «Криминализация российского уголовного законодательства в период пандемии».

Респондентам были заданы следующие вопросы:

1. Соблюдаете ли вы ограничительные меры, введенные в целях предупреждения распространения коронавирусной инфекции?

2. Считаете ли вы необходимостью привлечения к ответственности лиц, уклоняющихся от соблюдения таких ограничений?

3. Знаете ли вы, за совершение каких общественно-опасных деяний уголовное законодательство Китая, Израиля и Аргентины предусматривает ответственность?

4. Если да, то, на ваш взгляд, является ли это эффективным способом в борьбе с распространением коронавирусной инфекции?

5. По вашему мнению, позволит ли дисциплинировать нарушителей введение в российское законодательство уголовной ответственности за нарушение ограничительных мер?

И предложены варианты ответа: а) да; б) нет; в) затрудняюсь ответить.

По результатам проведенного исследования были получены вполне ожидаемые результаты (рис. 1). Более половины респондентов ответили, что отклоняются от соблюдения ограничительных мер либо затрудняются ответить на данный вопрос (62\%), оставшаяся часть граждан ответили положительно. Значительная доля (78 \%) граждан поддержали необходимость привлечения к ответственности лиц, которые уклоняются от соблюдения введенных ограничительных мер. На вопрос об ответственности в нормах уголовного законодательства Китая, Израиля и Аргентины - 64 \% респондентов ответили положительно, 36 \% - отрицательно. Также 64 \% граждан считают эффективным привлечение к уголовной ответственности в указанных странах в целях борьбы с распространением коронавируса, остальные $36 \%$ затруднились ответить на этот вопрос. Большинство респондентов также считают, что криминализация подобных деяний в российском уголовном законодательстве позволит дисциплинировать нарушителей ограничительных мер (86 \%).

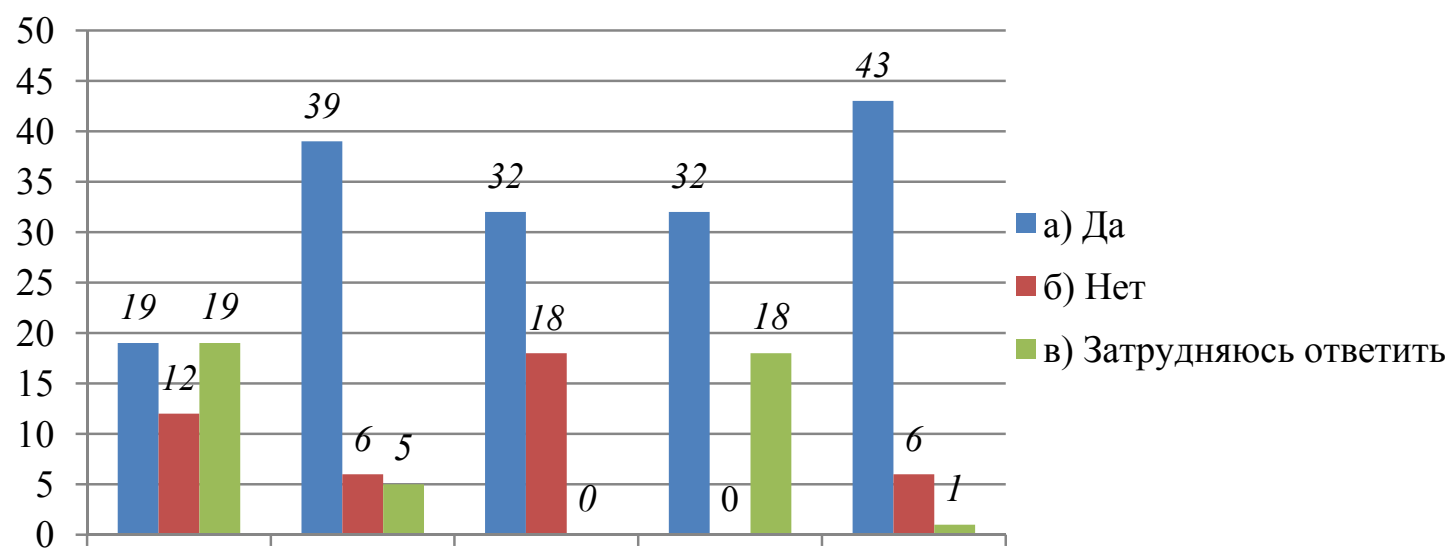

Вопрос 1 Вопрос $2 \quad$ Вопрос 3 Вопрос 4 Вопрос 5

Рис. Результаты опроса на тему «Криминализация российского уголовного законодательства в период пандемии»

На основании вышеизложенного с учетом результатов социологического исследования считаем целесообразным предусмотреть в российском уголовном законодательстве норму, касающуюся ответственности за нарушение распоряжения уполномоченного должностного лица (органа) об ограничениях в связи с тяжелыми инфекционными заболеваниями. Поскольку в случае ухудшения эпидемиологической обстановки распространения коронавирусной инфекции COVID-19 либо возникновения и последующего распространения иной инфекции, которой может быть причинен вред жизни и здоровью граждан указанная мера ответственности может стать эффективной, так как уголовная от- 
ветственность в качестве последствий для гражданина влечет наличие судимости. Исходя из этого дополнить УК РФ [2] ст. 236.1 - «Нарушение законного распоряжения об ограничениях в связи с распространением тяжелого инфекционного заболевания». Наказание за совершение такого преступления не должно превышать размер наказания за преступления небольшой тяжести.

Кроме того, исходя из опыта Китайской Народной Республики перспективно дополнить УК РФ статьей об ответственности за производство и реализацию некачественных лекарственных средств, а также за продажу лекарственных средств по завышенной стоимости, касающихся профилактики инфекций. В качестве квалифицирующего признака возможно совершение указанных действий лицом с использованием служебного положения. В связи с этим ввести в УК РФ [2] ст. 235.2 - «Производство и реализация некачественных лекарственных средств по профилактике инфекций», в ч. 2 предложенной статьи изложить самостоятельный состав - «Незаконная продажа лекарственных средств по профилактике инфекций по завышенной стоимости», в ч. 3 указать квалифицирующий признак «деяния, предусмотренные ч. 1 и ч. 2, лицом с использованием своего служебного положения». Данное деяние отнести к преступлениям средней тяжести.

Следует отметить, что законодатель не остался в стороне с начала распространения пандемии. Так, например, в ст. 236 - «Нарушение санитарно-эпидемиологических правил» УК РФ были в значительной степени увеличены санкции. Часть 1 ст. 236 УК РФ предусматривает наступление ответственности за совершение общественно-опасного деяния, выраженного в форме нарушения санитарноэпидемиологических правил, повлекшее по неосторожности массовое заболевание или отравление людей или же создавшее угрозу наступления таких последствий. Ранее в данной правовой норме отсутствовала «угроза наступления последствий» в виде массового заболевания или отравления людей из-за нарушения санитарно-эпидемиологических правил. Санкция ч. 1 ст. 236 УК РФ предусматривает такие наказания, как штраф в размере до 700 тыс. рублей (ранее максимальный его размер составлял 80 тыс. рублей), ограничение свободы на срок до 2 лет (ранее - до года). Также санкция дополнена наказаниями в виде принудительных работ на срок до 2 лет, а также лишением свободы на тот же срок.

Законодатель разграничил ответственность за нарушение санитарно-эпидемиологических правил, повлекшее причинение по неосторожности смерти человека (ч. 2 ст. 236 УК РФ) и повлекшее по неосторожности смерть двух или более лиц (ч. 3 ст. 236 УК РФ). Максимальный размер наказания в виде лишения свободы особо квалифицированного состава преступления равен 7 годам.

А в Киргизии за совершение подобного рода деяния, выразившегося в нарушении санитарноэпидемиологических правил и вызвавшее массовое заболевание граждан, предусмотрен штраф в размере около 4 тыс. долларов либо лишение свободы до 5 лет [9].

Итак, уголовная ответственность за нарушение санитарно-эпидемиологических правил в правовых нормах зарубежного законодательства гораздо строже, чем в УК РФ. Если в Киргизии нарушение указанных норм вызвало массовую заболеваемость, то максимальный размер наказания в виде лишения свободы достигает 5 лет, а в России лишение свободы не превышает 2 лет, в том случае если деяние совершено по неосторожности.

Наглядным примером по факту нарушения санитарно-эпидемиологических требований, повлекшее по неосторожности массовое заболевание сотрудников склада ООО «Абсолют», могут послужить проверочные мероприятия, организованные Прокуратурой Свердловской области. По данным территориального отдела Управления Федеральной службы по надзору в сфере защиты прав потребителей и благополучия человека по Свердловской области, установлено, что всего в указанных складских помещениях работает 870 человек. В период с 5 по 26 мая 2020 г. среди сотрудников склада ООО «Абсолют» было зафиксировано 180 случаев заболевания коронавирусной инфекцией (COVID-19).

По результатам проведения прокурорской проверки отмечено, что в условиях необходимости принятия дополнительных мер по снижению рисков распространения коронавирусной инфекции и введения ограничительных мероприятий на складе не были соблюдены требования законодательства о санитарно-эпидемиологическом благополучии населения.

С учетом выявленных нарушений санитарно-эпидемиологических требований в работе склада прокуратурой Свердловской области были направлены материалы для дачи уголовно-правовой оценки на наличие признаков состава преступления, предусмотренного ст. 236 УК РФ, в органы предварительного следствия. После чего органами следствия по материалам прокурорской проверки было возбуждено уголовное дело по ч. 1 ст. 236 УК РФ [17]. 
По нашему мнению, следует рассмотреть и сравнительно новую в российском уголовном законодательстве ответственность, связанную с распространением информации о коронавирусной инфекции COVID-19.

Для этого первоначально обратим внимание на справедливое заключение К.А. Волкова об определении преступлений, связанных с нарушением мер по противодействию распространению новой коронавирусной инфекции COVID-19. По его мнению, это совокупность уголовно наказуемых общественно опасных деяний, запрещенных нормами уголовного закона, которые совершаются в период применения усиленных мер по противодействию распространению новой коронавирусной инфекции COVID-19, причиняют (создают угрозу причинения) существенный вред личности, обществу и государству [6. С. 55].

Борьбу с распространением ложной информации как общественно-опасного деяния, причиняющего вред личности, обществу и государству, изначально осуществляли в добровольном порядке, однако когда массовая паника начала угрожать безопасности, органы власти некоторых стран начали принимать более жесткие меры. Россия не стала исключением и ввела уголовную ответственность за такие действия.

В качестве основной причины ужесточения ответственности можно назвать рост привлечения лиц к административной ответственности по ч. 9 ст. 13.15 «Злоупотребление свободой массовой информации» Кодекса Российской Федерации об административных правонарушениях (далее - КоАП РФ) [1], то есть за распространение заведомо недостоверной общественно значимой информации под видом достоверных сообщений, создавшее угрозу причинения вреда жизни либо здоровью граждан, а также угрозу массового нарушения общественного порядка или общественной безопасности.

Приведем пример из судебной практики по административному делу, в целях уяснения того, что же понимается под распространением заведомо недостоверной информации, представляющей общественное значение. Так, Заводской районный суд г. Саратова установил, что в сети «Интернет» на сайте «Одноклассники» в сообществе «Типичный Саратов» при обсуждении статьи под названием «Коронавирус» пользователь под сетевым именем «Любовь А.» Абросимова Л.Л. разместила следующий комментарий: «Знакомый болел, не имея отношения к вирусу, при выписке предложили деньги, чтобы сказал, что болел этим вирусом». Абросимова Л.Л. была признана судом виновной в совершении административного правонарушения, предусмотренного ч. 9 ст. 13.15 КоАП РФ, ей было назначено наказание в виде административного штрафа в размере 15 тыс. рублей без конфискации предмета административного правонарушения [14].

Таким образом, Абросимова Л.Л. осознавала, что публично размещает недостоверную информацию под видом достоверной, создающую угрозу общественной безопасности. В данном случае к недостоверной информации относится высказанный о болезни знакомого комментарий, который указывает на опровержение пандемии, а значит, может привести к таким негативным последствиям, как уклонение от соблюдения гражданами ограничительных мер, создание паники и дезориентация населения, причинение психологического ущерба гражданам.

В связи с распространением в социальных сетях, новостных и иных интернет-ресурсах недостоверной информации об обстоятельствах, представляющих угрозу жизни и безопасности граждан, то есть о коронавирусной инфекции, которая официально внесена в Перечень заболеваний, представляющих опасность для окружающих [4] в УК РФ Федеральным законом от 01.04.2020 №100-Ф3 были введены два состава: ст. 207.1 «Публичное распространение заведомо ложной информации об обстоятельствах, представляющих угрозу жизни и безопасности граждан» и ст. 207.2 «Публичное распространение заведомо ложной общественно значимой информации, повлекшее тяжкие последствия» [3].

Видовым объектом вышеуказанных составов являются отношения в сфере общественной безопасности, что подтверждает повышенную опасность коронавирусной инфекции, а также вред, который может быть причинен гражданам путем распространения ложной информации под видом достоверной.

Что же следует понимать под ложной информацией, указанной в ст. 207.1 и ст. 207.2 УК РФ? Обратимся к обзору судебной практики.

Согласно «Обзору по отдельным вопросам судебной практики, связанным с применением законодательства и мер по противодействию распространению на территории Российской Федерации новой коронавирусной инфекции (COVID-19) №2», утвержденному Президиумом Верховного Суда РФ 30.04.2020 г., для целей ст. 207.1 и ст. 207.2 УК РФ под заведомо ложной информацией, в том числе 
об обстоятельствах распространения на территории Российской Федерации новой коронавирусной инфекции (COVID-19) и (или) о принимаемых в связи с этим мерах по обеспечению безопасности населения и территорий, приемах и способах защиты от указанных обстоятельств, следует понимать такую информацию (сведения, сообщения, данные и т. п.), которая изначально не соответствует действительности, о чем достоверно было известно лицу, ее распространявшему [5].

$\mathrm{B}$ «Обзоре по отдельным вопросам судебной практики, связанным с применением законодательства и мер по противодействию распространению на территории России новой коронавирусной инфекции (COVID-19) №2» также указано: о придании ложной информации вида достоверной могут свидетельствовать, например, формы, способы ее изложения (ссылки на компетентные источники, высказывания публичных лиц и пр.), использование поддельных документов, видео- и аудиозаписей либо документов и записей, имеющих отношение к другим событиям [5].

Максимальный размер наказания по данным составам - лишение свободы на срок до 5 лет, минимальный штраф в размере от 300 до 700 тыс. рублей. Любое уголовное наказание влечет наличие судимости, поэтому следует внимательно относится к распространяемой информации, которая может содержать сведения об обстоятельствах коронавирусной инфекции, особенно если она распространяется публично.

Приведем практический пример по ст. 207.1 УК РФ. Органом предварительного следствия Юрченко А.С. подозревается в публичном распространении под видом достоверных сообщений заведомо ложной информации об обстоятельствах, представляющих угрозу жизни и безопасности граждан, поскольку при помощи своего сотового телефона «Samsung», с подключением к сети «Интернет», зашел на свою персональную страницу в социальной сети «ВКонтакте», после чего, действуя незаконно, будучи осведомленным о принципах работы данного ресурса, осознавая, что указанный ресурс является популярным среди населения, постоянно используется и посещается лицами, обладающими возможностью доступа к сети передачи данных, осознавая общественную опасность своих действий, с целью провокации паники, страха и беспокойства у неопределенного круга лиц, публично распространил под видом достоверного сообщения заведомо ложную информацию об обстоятельствах, представляющих угрозу жизни и безопасности граждан, разместив в публичном сообществе «Подслушано в Нефтеюганске» под одним из постов, размещенных неизвестным пользователем, комментарий о том, что он болен новой коронавирусной инфекцией (COVID-19) и гуляет по городу, заражая людей, что является заведомо ложной и недостоверной информацией, которую Юрченко А.С. выдал за истинную и убедил в этом других лиц. Впоследствии уголовное дело по подозрению Юрченко А.С. в совершении преступления, предусмотренного ст. 207.1 УК РФ, было прекращено судом по результатам рассмотрения ходатайства следователя о прекращении уголовного дела по подозрению Юрченко А.С. с назначением меры уголовно-процессуального характера в виде судебного штрафа. Нефтеюганским районным судом Ханты-Мансийского автономного округа - Югры Юрченко А.С. назначена мера уголовно-правового характера в виде судебного штрафа в размере 50 тыс. рублей [15].

Аналогичным примером может служить постановление Буйнакского городского суда Республики Дагестан по ходатайству следователя о прекращении уголовного дела (уголовного преследования) по ст. 207.1 УК РФ в отношении Сурхаева Д.М. с назначением ему меры уголовно-правового характера в виде судебного штрафа. По материалам уголовного дела было установлено, что примерно в третьей декаде апреля 2020 г., не позднее 29 апреля 2020 г., Сурхаев Д.М., используя мобильный телефон, с доступом к сети «Интернет», разместил посредством мессенджера «WhatsApp» в групповом чате под названием «Весовой контроль $3 »$, с общим количеством участников 253 человека, голосовое сообщение, содержащее заведомо ложную информацию об обстоятельствах, представляющих угрозу жизни и безопасности граждан, а именно сведения о распространении новой коронавирусной инфекции (COVID 19) над территорией г. Буйнакска Республики Дагестан посредством вертолетов, в результате чего якобы на территории г. Буйнакска стали погибать люди. Впоследствии указанная информация была распространена в других групповых чатах мессенджера «WhatsApp», а также в иных социальных сетях. Суд также прекратил уголовное дело и назначил Сурхаеву Д.М. меру уголовноправового характера в виде судебного штрафа в размере 10 тыс. рублей [16].

Таким образом, на основании анализа судебной практики можно сделать вывод о том, что, как правило, производство по уголовным делам, возбужденным по ст. 207.1 УК РФ в связи с распространением ложной информации, содержащей сведения о коронавирусной инфекции и представляющей угрозу жизни и безопасности граждан, прекращается. Также получается, что назначение администра- 
тивного наказания по ч. 9 ст. 13.15 КоАП РФ в виде штрафа, согласно приведенным примерам, приравнивается к размеру судебного штрафа в связи с прекращением уголовных дел по ст. 207.1 УК РФ.

Говоря о рентабельности уголовной ответственности за распространение недостоверных (ложных) сведений о коронавирусной инфекции, которые могут повлечь за собой последствия в виде создания препятствий для реализации мер, направленных на предупреждение распространения коронавируса; провокации паники и дезориентации населения, причинения психологического ущерба гражданам, рекомендуется учитывать повышенную общественную опасность преступного деяния, и в случае прекращения судом уголовного дела и назначения меры уголовно-правового характера в виде судебного штрафа устанавливать размер такого штрафа не менее суммы, предусмотреной санкцией ч. 9 ст. 13.15 КоАП РФ, то есть не менее 100 тыс. рублей для граждан и 200 тыс. рублей для лиц, совершивших противоправное деяние с использованием своего служебного положения.

В других странах также предусмотрена уголовная ответственность за распространение недостоверной информации, однако введена она была до возникновения пандемии. Например, в США в уголовных кодексах нескольких штатов прямо предусмотрена ответственность за распространение сомнительной или недостоверной информации, при этом санкция закрепляет штрафы в размерах, равных нескольким сотням тысяч долларов. Аналогичные нормы предусмотрены и в уголовном законодательстве Франции, где за подобные действия может быть назначен штраф до 40 тыс. евро или тюремный срок до 5лет.

Таким образом, перспективное ужесточение юридической ответственности в условиях распространения коронавирусной инфекции в России возможно с учетом положительного и отрицательного опыта других стран, которые уже на протяжении длительного периода ведут борьбу с коронавирусной инфекцией COVID-19, предпринимают своевременные и во многом эффективные меры, в том числе и ужесточение ответственности по противодействию её распространению, а также в эффективном применении и совершенствовании уже имеющихся норм уголовного законодательства.

\section{СПИСОК ЛИТЕРАТУРЫ}

1. Кодекс Российской Федерации об административных правонарушениях: федеральный закон от 30.12 .2001 № 195-Ф3 // Российская газета. 2001. 31 дек.

2. Уголовный кодекс Российской Федерации: федеральный закон от 13.06.1996 №63-Ф3 // Собрание законодательства РФ. 1996. № 25. Ст. 2954.

3. О внесении изменений в Уголовный кодекс Российской Федерации и статьи 31 и 151 Уголовнопроцессуального кодекса Российской Федерации: федеральный закон от 01.04.2020 № 100-Ф3 // Российская газета. 2020. 3 апр.

4. Об утверждении перечня социально значимых заболеваний и перечня заболеваний, представляющих опасность для окружающих: постановление Правительства РФ от 01.12.2004 № 715 // Российская газета. 2004. 7 дек.

5. Обзор по отдельным вопросам судебной практики, связанным с применением законодательства и мер по противодействию распространению на территории Российской Федерации новой коронавирусной инфекции (COVID-19) №2 (утв. Президиумом Верховного Суда РФ 30.04.2020) // Бюллетень Верховного Суда РФ. 2020. № 6.

6. Волков К.А. Новая коронавирусная инфекция (COVID-19) и уголовный закон // Российская юстиция. 2020. № 7. C. 52-55.

7. Шумских Ю.Л. Ужесточение юридической ответственности в условиях коронавируса // Вестник Волжского ун-та им. В.Н. Татищева. 2020. № 3, т. 1. С. 56-63.

8. Интернет-портал: wikipedia. Коронавирусы. [Электронный ресурс]. URL: https://ru.wikipedia.org/wiki/

9. Интернет-портал: genproc.gov.ru. По материалам прокуратуры возбуждено уголовное дело по факту нарушения санитарно-эпидемиологических правил на складе крупной торговой сети, повлекшего по неосторожности массовое заболевание сотрудников. [Электронный ресурc]. URL: https://genproc.gov.ru/

10. Интернет-портал: rospotrebnadzor.ru. Эпидемиологическая обстановка и распространение COVID-19 в мире. [Электронный ресурс]. URL: https://rospotrebnadzor.ru/

11. Интернет-портал: OKPRAVO.RU. Уголовный кодекс КНР. [Электронный pecypc]. URL: http://okpravo.ru/ zarubezhnoe-pravo/ugolovnoe-pravo-zarubezhnyh-stran

12. Интернет-портал: OKPRAVO.RU. Закон об уголовном праве Израиля 1977 г. [Электронный pecypc]. URL: http://okpravo.ru/zarubezhnoe-pravo/ugolovnoe-pravo-zarubezhnyh-stran

13. Интернет-портал: OKPRAVO.RU. Уголовный кодекс Аргентины. [Электронный pecypc]. URL: http://okpravo.ru/zarubezhnoe-pravo/ugolovnoe-pravo-zarubezhnyh-stran - 
14. Интернет-портал: sudact.ru. Постановление № 5-588/2020 от 16 июля 2020 г. по делу № 5-588/2020 Заводского районного суда г. Саратова (Саратовская область). [Электронный ресурc]. URL: https://sudact.ru/regular/

15. Интернет-портал: sudact.ru. Постановление № 1-305/2020 от 27 мая 2020 г. по делу № 1-305/2020 Нефтеюганского районного суда (Ханты-Мансийский автономный округ-Югра). [Электронный pecypc]. URL: https://sudact.ru/regular/

16. Интернет-портал: sudact.ru. Постановление № 1-110/2020 от 2 июля 2020 г. по делу № 1-110/2020 Буйнакского городского суда (Республика Дагестан). [Электронный ресурс]. URL: https://sudact.ru/regular/

17. Интернет-портал: TASS.RU. Какое наказание грозит за нарушение карантинных мер при коронавирусе в разных странах. [Электронный ресурс]. URL: https://tass.ru/info/7989649

Поступила в редакцию 15.02.2021

Гафурова Эльмира Равилевна, кандидат юридических наук, доцент

ФГБОУ ВО «Ижевский государственный технический университет им. М.Т. Калашникова»

426000, Россия, г. Ижевск, ул. Студенческая, 7

\section{E.R. Gafurova \\ ON THE ISSUE OF CRIMINALIZATION OF CRIMINAL ACTS RELATED TO THE SPREAD OF CORONAVIRUS INFECTION}

DOI: $10.35634 / 2412-9593-2021-31-2-243-250$

The article deals with the issues of improving the Russian criminal legislation on toughening responsibility in the context of coronavirus infection. The author analyzes the effectiveness of measures to tighten criminal liability for violations of quarantine measures in order to counter the spread of coronavirus infection in foreign countries and presents proposals for improving Russian criminal legislation, taking into account the data of a sociological study conducted among citizens of the Russian Federation. In order to study the norms of criminal legislation introduced by Federal Law No. 100-FZ of 01.04.2020, on liability for the dissemination of deliberately false information about circumstances that pose a threat to the life and safety of citizens, examples of judicial practice are given. There is a promising tightening of legal liability in the context of the spread of coronavirus infection in Russia based on the experience of foreign countries.

Keywords: legal liability, criminal liability, increased liability, criminalization, coronavirus infection, pandemic, restrictions, false information.

Gafurova E.R., Candidate of Law, Associate Professor

Izhevsk State Technical University named after M.T. Kalashnikov

Studencheskaya st., 7, Izhevsk, Russia, 426069 